\title{
Una violeta de más, de Francisco Tario: crueldad, humor y praxis
}

Inés Ferrero Cándenas

Universidad de Guanajuato

\section{Resumen}

Este artículo analiza algunos cuentos de Francisco Tario, contenidos en $\mathrm{La}$ noche y Una violeta de más desde la perspectiva de una estética de la crueldad. Se subraya la similitud entre los procedimientos del narrador mexicano y los conceptos del teatro de la crueldad de Artaud. Sin embargo, si Artaud eleva el acto cruel a un nivel místico en el que la crueldad equivale a plenitud de vida, Tario lo presenta sobre todo como acto de liberación que nos permite ver nuestra propia insignificancia.

Palabras clave: crueldad, Artaud, humor, praxis, liberación.

\section{Abstract}

This article analyses some short stories by Francisco Tario, published in $\mathrm{La}$ noche and Una violeta de más applying the esthetics of cruelty. The similitude between the proceedings of the Mexican writer and Artaud's theater of cruelty are shown in the article. Nevertheless, in Artaud cruel acting has a mystical level where cruelty signifies life's plenitude. Tario, on the other hand, sees an aspect of liberation in cruelty that reveals our own insignificance.

Keywords: cruelty, Artaud, humor, praxis, liberation. 
$Y^{2}$ a sea por su precaria forma de adentrarse en la historia de la literatura mexicana, ya sea por su tendencia a crear imaginarios extravagantes o por el simple hecho de que la crítica lo ha ignorado durante las últimas décadas, Francisco Tario con frecuencia ha sido considerado un escritor "raro" o "secreto" (ver Toledo, 2006: 8). Dicho de otra forma, un autor ligado a la palabra anticanónico. ¿Por qué? En el primero de sus libros, La noche, el narrador resume lo que podría entenderse como el programa estético y vital del propio autor:

Y escribiré libros. Libros que paralizarán de terror a los hombres que tanto me odian; que les menguarán el apetito; que les espantarán el sueño; que trastornarán sus facultades y les emponzonarán la sangre. Libros que expondrán con precisión inigualable lo grotesco de la muerte, lo execrable de la enfermedad, lo risible de la religión, lo mugroso de la familia y lo nauseabundo del amor [...] Libros, en fin, que estrangulen las conciencias, que aniquilen la salud, que sepulten los principios y trituren las verdades. Exaltaré la lujuria, el satanismo, la herejía, el vandalismo, la gula, el sacrilegio: todos los excesos y las obsesiones más sombrías, los vicios más abyectos, las aberraciones más tortuosas (Tario, 1943: 54).

En este fragmento podemos observar, si no la "rareza" de su propuesta literaria, sí ciertas características que lo acercan a aquellos escritores "raros" entendidos por Rubén Darío como de escritores marginales, inclasificables o underground (1952: 23-26). El mismo fragmento es utilizado por Geney Beltrán en un monográfico sobre la obra de Francisco Tario y Efrén Hernández con el fin de subrayar que la rabia radical de los primeros libros de Tario se ha difuminado en los últimos: Tapioca Inn y Una violeta de más (2006: 184).

Sin embargo, un breve recorrido a través de las páginas de Una violeta de más parece poner en entredicho tal afirmación. Esta colección de cuentos fantásticos publicada en diciembre de 1968 se 
abre con "El mico", relato que narra principalmente la historia de un infanticidio y se cierra con "Entre tus dedos helados", historia de un joven que, al estilo de Espronceda, asiste a su propio funeral gracias a las maquinaciones de su hermana-amante. A estas dos historias habría que añadirle "Ragú de ternera", donde un antropófago mete a un recién nacido en el horno y acompanándose de un buen vaso de vino, lo corta en trocitos para comérselo, u "Ortodoncia", en el que una familia se ríe de la falta de dientes de uno de sus miembros hasta provocar su suicidio. A juzgar por la temática y línea argumentativa de los relatos mencionados, se diría que en el último de los libros de Tario el programa estético anunciado por el primero de sus personajes sigue vigente; esto es, Una violeta de más continúa exponiendo "lo grotesco de la muerte, lo execrable de la enfermedad, lo risible de la religión, lo mugroso de la familia y lo nauseabundo del amor" (Tario, 1943: 54).

Sin duda su prosa ha cambiado, pero el ataque contra las instituciones, la comunicación humana, el amor o la piedad no se han difuminado, sino evolucionado, dando lugar a un programa estético más sofisticado y complejo. Es precisamente una indagación sobre el programa estético de Tario en Una violeta de más lo que se abordará en el presente artículo. Se partirá de la premisa de que dicho programa es una continuación de lo anunciado por su primer narrador, dándole así cierta cohesión a su obra y elucidando que su estética está regida, no exactamente por una "rabia radical", sino por la crueldad.

¿Qué es la crueldad? Según la acepción de la Real Academia Española crueldad significa: "Inhumanidad, fiereza de ánimo, impiedad". Según la Asociación Americana de Psiquiatría la crueldad constituye un "disturbio psicológico caracterizado por una respuesta emocional de indiferencia, o de obtención de placer ante el sufrimiento y dolor de los demás" (Michael, 2005: internet). La crueldad es por tanto una característica psicológica, de una persona, de un autor, o de sus 
personajes. También es un tipo de estética: escritores y artistas crean imágenes de crueldad. Pero es algo más. Si aceptamos que "por ser tratado cruelmente, Sade creó crueles fantasías" (Zimmerman, 1977: 507) la crueldad como pieza básica de su investigación literaria no sólo es un tipo de expresión estética, sino una forma de praxis: dichas fantasías ofrecieron a Sade la posibilidad de venganza contra sus opresores, contra una sociedad que lo encarceló y marginó (Zimmerman, 1977: 509). Tenemos así que aparte de la común acepción de la crueldad como alteración psicológica, ésta puede constituir una estética, y también un modo de praxis. La pregunta a formular respecto a la colección de relatos de Tario es entonces, ¿En qué consiste esta praxis? ¿Cómo funciona estéticamente y qué efecto produce en el lector?

Para acercarnos a posibles respuestas cabe introducir brevemente la noción de humor negro, concepto que veo estrechamente vinculado a la estética de la crueldad como praxis en Una violeta de más. El humor puede tomar numerosas direcciones. No es mi intención en el presente estudio definir o analizar las posibles significaciones del humor como índole o condición humana (Bergson, 2008: 12-13); tampoco como un modo de representar una determinada realidad de forma que se resalte su aspecto cómico (Bergson, 2008: 16-17). Por el momento, bastará decir que cuando la realidad a representar está caracterizada por los aspectos más sombríos o siniestros de la condición humana, como pueden serlo la crueldad o la muerte, y dicha realidad es representada de forma cómica, se habla comúnmente de humor negro. De nuevo se podría hablar de varias direcciones en esta acepción del humor. Nos ajustaremos a una en particular, entendiendo el humor negro presente en Una violeta de más en el marco de la ruptura y la herencia de las vanguardias europeas, particularmente del surrealismo. 
Desde la perspectiva surrealista, el humor negro no sólo es un concepto vinculado a la muerte, a lo siniestro o macabro enfocado desde un punto de vista sarcástico e irónico. En su Antología del humor negro (1939), André Breton lo define como un tipo particular de "emoción subversiva que tiene por objeto atacar el bienestar de todo aquello que se considere estable" (1997: 14). Años más tarde y siguiendo a Breton, John D. Erickson concibe el humor negro surrealista como un "intento por descubrir y articular un nuevo discurso que ofrezca una alternativa a la representación del mundo impuesta por la visión dominante de la clase media occidental" (1998: 198). Por un lado, el humor negro presente en Una violeta de más se alía con la concepción surrealista en tanto que su discurso humorístico está destinado a desequilibrar los principios más sólidos sobre los que se basan las relaciones humanas y por tanto a ofrecer una alternativa a la representación del mundo impuesta por la clase media occidental. A saber: el respeto a la vida, los vínculos afectivos, las instituciones sociales, la comunicación entre sujetos. Por otro lado, el modo en el que el humor negro se inserta en los relatos de Tario puede vincularse con la idea de praxis propuesta por la estética de la crueldad que defendía el surrealismo y, en particular, Antonin Artaud, quien escribe en "Cartas acerca de la crueldad":

No cultivo el horror de manera sistemática. La palabra crueldad será entendida en un sentido amplio y no en el que se le otorga habitualmente. Y reivindico el derecho de quebrantar los significados usuales del lenguaje, de destruir de manera definitiva la coraza, haciendo trizas el collar de hierro; en fin, de retornar a las etimologías del lenguaje que a través de conceptos abstractos evocan elementos concretos (2002: 99).

La palabra crueldad para Artaud no implica necesariamente perversión, sadismo o violencia en la vida cotidiana. Su forma de quebran- 
tar el significado usual que se asigna a la palabra crueldad abarca una visión de este concepto que no está necesariamente unida al desgarramiento de la carne, sino al determinismo filosófico: a aquel tipo de conciencia que "otorga al ejercicio de vida su matiz de sangre, porque se sobreentiende que la vida ha de incluir siempre a la muerte" (Artaud, 2002: 100). El significado que comúnmente asignamos a la palabra crueldad (ver definiciones enciclopédicas anteriores) puede así trascender su significado. El matiz de sangre puede servir para enseñarnos otro aspecto de lo humano, no de lo inhumano.

Para Artaud la estética de la crueldad tiene una propiedad "curativa”, pues considera que ésta es capaz de eliminar cierto tipo de sentimientos que expresamos de forma destructiva; que puede llegar a purgar nuestros impulsos sangrientos. La estética de la crueldad tal y como es concebida por Artaud no se identifica necesariamente con la percepción simbólica de un rigor sangriento o tortuoso, sino que es una estética que se identifica con lo plástico y lo físico, lo mítico y lo mágico para producir un lenguaje que privilegie lo corporal y apele no sólo al entendimiento psicológico o racional, sino también a una percepción sensorial que llegue de forma convulsiva al sentimiento del espectador (Artaud, 2002: 100-104). Dicho de otro modo: la estética de la crueldad es entendida como praxis.

Artaud no pretende acabar con la mentira y decepción humanas tal y como se encuentren en un determinado momento dentro de una sociedad concreta. No se trata literalmente de transformar la sociedad en la que vivimos, sino de insertar en ésta elementos que hagan que el sujeto se libere de sus propias limitaciones, que lo hagan despertar de una conducta regida por la inercia: "considero imposible revitalizar el mundo en el que vivimos y además, inútil aferrarse a él; propongo algo que nos arranque de tal marasmo en lugar de continuar quejándonos de él, del aburrimiento, la inercia y la estupidez generalizada" (81). Artaud incluye en su teatro de la crueldad ele- 
mentos grotescos, macabros y crueles como vehículos para crear una estética capaz de hipnotizar la sensibilidad del espectador (80). ${ }^{1}$

La estética de la crueldad se diferencia así de la crueldad como alteración psicológica en que ésta vendría a convertirse en un modo de "liberar" al hombre de su propia represión, provocando que vuelva a sí mismo. Una praxis dirigida a causar la caída de la máscara, a dejar que salga a la luz la hipocresía que él ve en las sociedades occidentales, a impulsar a los hombres a que se observen "tal y como son". La meta de Artaud no es en este aspecto muy diferente a la propuesta por el psicoanálisis freudiano: proyectar una cura cuyo proceso involucra una experiencia de shock, de confrontación con ciertos deseos suprimidos. El objetivo es destruir la complacencia, acabar con las pautas mentales y emocionales tal y como nos vienen dadas. El camino es encararse, una y otra vez, a una irrevocable destrucción hasta que finalmente se transcienda. Bajo la visión de Artaud, la exaltación de la crueldad en el arte y la literatura constituye una praxis que tiene por objeto pasar de la turbación psicológica a la salud mental.

Existe, no obstante, una dificultad en entender la estética de la crueldad como praxis de liberación o cura, y esta dificultad emerge de uno de sus atributos básicos. La crueldad ataca al ser humano en su nivel más irracional, sin pretender o sin ser capaz de redirigir una conciencia total. Por lo tanto, la proyección artística o literaria de la crueldad puede dar lugar a una praxis contraria: aumentar el impulso agresivo de aquel que la contempla o experimenta. Si un hombre o una mujer disfruta de la lectura u observación de un acto inhumano, si alguien busca la expresión del dolor por goce está buscando la esté-

${ }^{1}$ Algo parecido a lo que Bertolt Brecht llamó estrangement effect o distanciamiento. El término de Brecht se define como aquello "which prevents the audience from losing itself passively and completely in the character created by the actor, and which consequently leads the audience to be a consciously critical observer" (1964: 61). 
tica de la crueldad como deleite, como método para obtener placer. Este sujeto podría buscar la crueldad en el plano estético de forma repetida, incluso con la necesaria ilusión de que lo que está haciendo es intentar traspasarla (como alteración psicológica). En dicho caso, confrontarse a la proyección de la crueldad no le ayudará a traspasar el acto cruel en sí, sino que dicho acto se convertirá en su propia recompensa, en la forma de alimentar al monstruo.

En este contexto, la expresión artística de la crueldad como praxis puede funcionar de forma contraria a la concebida por Artaud. Es decir, puede satisfacer un hambre sadomasoquista programada. Se eliminaría así toda posibilidad liberadora en tanto que el valor o significado habitualmente otorgado a la palabra crueldad no es quebrantado ni se trasciende, sino que se reafirma. Artaud es consciente de esta dificultad y de que muchos adoptarán una postura escéptica: "Se afirmará que el ejemplo genera ejemplos, que si la actitud de curación induce a ella, la actitud del crimen inducirá al crimen. Dependerá de la forma y pureza con la que se hagan las cosas. Existe un riesgo" (81). Artaud no menciona tal riesgo, pero es sin duda que, en efecto, la estética de la crueldad no sólo puede no "quebrantar los significados usuales del lenguaje" (Artaud, 2002: 99) y por tanto no funcionar como praxis liberadora, sino que la acepción y por tanto la forma en la que percibimos y entendemos ordinariamente la crueldad (alteración psicológica caracterizada por inhumanidad) puede verse alimentada por este tipo de estética. Bajo esta óptica, la estética de la crueldad como praxis "revolucionaria" concebida por Artaud parecería cualquier otra praxis de liberación propuesta que falla a la hora de trascender el campo al que entra. No obstante, "dependerá de la manera en la que se hagan las cosas" (Artaud, 2002: 81). La pregunta a formular en el caso de Una violeta de más es: ¿Y si las cosas se hacen con humor? Si la crueldad se representa a través de un discurso humorístico, ¿Podría entonces su estética funcionar como praxis de liberación? ¿Trascender realmente el campo al que entra? 
En Una violeta de más la posibilidad de entender la estética de la crueldad como praxis de liberación se articula al establecer ésta una estrecha relación con el humor negro. Si la crueldad como característica psicológica consiste en la indiferencia u obtención de placer ante el sufrimiento de los demás, ¿Es esta característica acentuada al presentarla con un discurso humorístico? ¿ $\mathrm{O}$ es al contrario el humor una forma de redimir su efecto, de observarlo desde arriba y distanciarse? Encararse a la crueldad con humor puede conducirnos a un estado más liviano, a una suerte de levedad en el ser, pero... ¿es esto una cura o la parte más peligrosa de la enfermedad?

Una violeta de más presenta un mundo esperpéntico. Narradores y protagonistas son reducidos a meras caricaturas de sí mismos, cosificados o animalizados. Todos los relatos, sin excepción, mezclan el mundo de la vigilia con el de la pesadilla, proponiendo a la muerte como personaje esencial. Cada relato distorsiona de forma sistemática la realidad para exponer una visión de la naturaleza humana regida por lo siniestro y lo sórdido: suicidios, asesinatos de diversa índole, actos de canibalismo y vampirismo, burla ante el dolor de seres queridos o personajes que sólo pueden ser saciados con las perversiones más insólitas.

En "El mico" se narra la experiencia de un hombre que contempla atónito cómo de su inodoro sale un ser extraño, una mezcla entre mono y recién nacido. Día a día la relación entre ambos crece en el plano afectivo, hasta el punto que el mico llama "mamá" al narrador y éste siente el deseo de darle un hermanito. Poco después se queda embarazado. Dándose cuenta de lo absurdo de su situación, el narrador resuelve deshacerse de la extraña criatura. Nos cuenta cómo:

Abrí la puerta del baño, cogí atolondradamente a la criatura y la sostuve en alto [...]. Le estreché fuertemente contra mi pecho, lo miré por última vez y lo arrojé al inodoro. Fue un acto cruel, -recuerdo- mas, a fin de cuentas, era de allí de donde él procedía [...] Eso 
me confortó, en lo que cabe. Con el agua al cuello, todavía me miró confuso [...] e hizo ademán de salir. Pero yo lo retuve allí, oprimiéndole la cabeza (Tario, 1968: 28).

Unas horas más tarde, al darse cuenta de lo que ha hecho, el narrador no puede contener un tremendo ataque de risa.

En "Ortodoncia" el padre del narrador, desprovisto de dientes, busca sin éxito una dentadura capaz de ajustarse a su boca. Esto le da un aspecto esperpéntico, provocando la burla constante de su familia. Eventualmente, le aparece una muela. La cuida amorosamente y el día de su cumpleaños decide festejarlo comiéndose una avellana. Se la introduce en la boca y deja caer la mandíbula sobre ella. Operación exitosa. Aplausos por parte de la familia. A la mañana siguiente, una llamada telefónica informa que el padre ha sido arrollado por un tranvía. Sobre la cama está su muela, con trozos de avellana incrustados en ella. El final del relato confirma que fue la mofa de sus hijos y mujer lo que provocó el suicidio del padre; al no soportar éste verse de nuevo sin dientes. El narrador termina su relato afirmando: "todavía hoy se me saltan de rabia las lágrimas cada vez que sorprendo a mi madre, sentada en un rincón de la sala, comiendo avellanas e inquiriendo de todo el mundo de la casa, en un tono que no deja de ser burlón- ¡Adivina! Adivina a qué me recuerda esto” (Tario, 1968: 167).

El humor negro que impregna ambos relatos, ese que se desprende de la actitud que adopta el hombre que mata a su absurdo "hijo" o de la esposa que se burla cuando algo le evoca la absurda muerte de su marido, existe sólo como respuesta a un acto cruel. Por un lado podríamos considerar que en ambos relatos el humor negro intensifica la praxis negativa de la crueldad en tanto que subraya lo inhumano del sujeto capaz de extraer cierta comicidad de semejantes actos. No obstante, si observamos con más detenimiento, vemos que funciona como método para distanciarse del acto cruel, para obser- 
varlo desde arriba. La estética de la crueldad según Artaud puede reconciliarnos con el orden establecido de las cosas porque deja exhaustas nuestras emociones negativas, pero ¿no es necesaria una postura humorística para que dichas emociones en realidad se trasciendan? En el prólogo de la ya mencionada antología del humor negro Breton cita la siguiente observación de Freud sobre el humor:

El humor produce un efecto liberador en el ser, pero también produce una suerte de grandeza y elevación [...] Esa grandeza radica en el triunfo del narcisismo, en la afirmación victoriosa de la invulnerabilidad del ego. El ego se niega a sufrir. Insiste en que no puede ser afectado por los traumas del mundo exterior. $Y$ de hecho nos muestra que dichos traumas no son más que oportunidades para que el ego obtenga placer (43).

Considerando la crueldad como posible ejemplo de ese trauma vemos que si mediante la levedad producida por el humor el ego niega la existencia de la crueldad, si se cree invulnerable a su efecto, una estética de la crueldad presentada a través de un discurso humorístico es una oportunidad para que el ego obtenga placer, para que se "esconda" de los traumas del mundo exterior. De esta forma, puede argumentarse que la alteración psicológica negativa que caracteriza la crueldad es atenuada a medida que su proyección estética profundiza en el discurso humorístico. En "El mico" el tono sarcástico que se desprende de la narración en primera persona atenúa la aprehensión provocada en el lector por el acto de infanticidio. En "Ortodoncia" el tono cómico con el que el narrador relata la reacción de la familia ante el suicidio del padre reduce la gravedad del hecho en sí, provocando que el lector deje en un segundo plano principios de la conducta humana como pueden ser los vínculos afectivos y de sangre. ${ }^{2}$

${ }^{2}$ Se está considerando el sarcasmo y lo cómico como componentes del discurso humorístico. 
Ambos relatos postulan una estética de la crueldad en tanto que en ellos se ven configuradas una serie de situaciones que investigan el origen sistemático del sentimiento de la crueldad y su representación literaria, pero también están enunciando dicha estética como praxis a través del efecto que ésta produce en el lector. El sufrimiento, la angustia o el aumento de nuestros impulsos agresivos son atenuados por el efecto liviano del humor, el cual facilita que el lector realice un gesto de separación sobre el acto cruel narrado al provocar un distanciamiento sobre el valor moral bajo consideración. En este sentido, la praxis de una estética de la crueldad articulada a través del humor negro sería la de conducir al lector hacia la indiferencia emocional ante el acto cruel, la de amortiguar el efecto psicológico que el acto cruel tiene en él, provocando así que el valor negativo que se asigna a la crueldad se trascienda. Esto es, en tanto que la crueldad deja de aludir a un valor externo para convertirse en la propia base de la realidad ficticia.

En "El mico" y en "Ortodoncia", pero también relatos como "Ragú de ternera", "Un inefable rumor" o "Ave María Purísima", el humor negro funciona en el lector como anestesia, duerme temporalmente todo sentimiento de piedad o culpa ante el acto cruel, apelando al intelecto, puro y simple. Esta suerte de anestesia permite que el sujeto sea de alguna forma rejuvenecido por la estética de la crueldad. Es decir, que el lector siga el principio de placer frente a los aspectos más sombríos de la existencia. Podríamos entonces concluir que en Una Violeta de más, la estética de la crueldad, impregnada por el discurso humorístico, sí funciona como praxis positiva: provoca distanciamiento, levedad y cierto placer. De esta forma, Tario podría estar añadiendo un nuevo giro al discurso de Artaud al subrayar lo esencial del componente humorístico en la estética de la crueldad para que ésta pueda realmente funcionar como praxis liberadora. 
A pesar de que Tario pareciera coincidir con Artaud en la afirmación de que "una acción violenta y concentrada es una suerte de lirismo: despierta imágenes sobrenaturales, una corriente sanguínea de imágenes, un borbollón sangriento de imágenes en el cerebro del poeta y en el del espectador" (Artaud, 2002: 80), mientras que la propuesta de Artaud consiste en crear una estética de la crueldad con el fin de producir una energía que eleve la vida y haga encontrar el orden, Tario sugiere que hemos de reírnos, liberarnos de esa búsqueda y reconocer que quizá sólo sirvamos para el desorden. Tario se burla de la posibilidad de una cura en la sociedad actual, y ésta es precisamente la praxis liberadora de su escritura: presentar un programa estético regido por la crueldad y el humor negro para exponer y desestabilizar las nociones de racionalidad, humanidad y progreso. En la última de sus obras, Tario completa el programa estético y vital anunciado en la primera: "estrangular las conciencias, aniquilar la salud, sepultar los principios y triturar las verdades" (Tario, 1943: 54). En otras palabras, transmitir una emoción subversiva al lector que tenga por objeto "atacar el bienestar de todo aquello que se considere estable". ${ }^{3}$ En Una violeta de más, Tario sugiere que es en el discurso humorístico de la estética de la crueldad y no en la estética de la crueldad en sí, donde radica la posibilidad de praxis liberadora. Liberadora en el sentido de una trascendencia de los valores que normalmente asignamos a la vida y al comportamiento humano, pero también de la significación que comúnmente asignamos a las palabras. Liberación del canon, del estancamiento de las ideas y del servilismo estético.

${ }^{3}$ Ver definición de humor negro dada por Breton, al comienzo de este artículo. 


\section{Bibliografía}

Artaud, Antonin, 2002, El teatro y su doble, trad. José R. Lieutier, México, Tomo.

B., Michael, "Dimensional Aspects of Psychiatric Diagnosis" en American Psychiatric Association; disponible en http://www.psych.org/.

Bergson, Henri, 2008, La risa. Ensayo sobre la significación de lo cómico, Madrid, Alianza.

Breton, André, 1997, Anthology of Black Humor, trad. Mark Polizzotti, San Francisco, City Light Books.

Brecht, Bertold, 1964, Brecht on Theater. The development of an aesthetic, trad. y ed. de John Willet, Nueva York, Hill and Wang.

Cabrera, Ana María, 2003, "El mundo de las irrealidades de Francisco Tario”, en Morales, Ana María, José Miguel Sardiñas y Luz Elena Zamundio (eds.), Lo fantástico y sus fronteras, México, Benemérita Universidad Autónoma de Puebla, pp. 205-214.

Dario, Rubén, 1952, Los raros, Buenos Aires, Espasa-Calpe.

Erickson, Jhon D., 1988, "Surrealist Black Humor as Oppositional Discourse”, en Symposium, núm. 42, pp. 198-236.

Beltrán Félix, Geney, “Tario furioso”, en Toledo, Alejandro (ed.), Dos escritores secretos. Ensayos sobre Efrén Hernández y Francisco Tario, México, Tierra Adentro, pp. 184-186.

Ortega, Julio, 2008, "Vuelta a Rubén Darío", en Revista de la Universidad de México, núm. 50; disponible en http://www.revistadelauniversidad. unam.mx/50/ortega/50ortega.html.

Tario, Francisco, 1943, La noche, Robredo, México. , 1943, Una violeta de más, Joaquín Mortiz, México. 
Toledo, Alejandro, 2006, "Prólogo", en Dos escritores secretos. Ensayos sobre Efrén Hernández y Francisco Tario, México, Tierra Adentro, pp. 7-11.

Zimmerman, Marc, 1977, "Sade et Lautréamont (sans Blanchot): Starting points for Surrealist Practice and Praxis in the Dialectics of Cruelty and Humour Noir”, en Boundary, vol. II, núm.5, pp. 507-528. 